\title{
Three-Dimensional simulation for the rock fragmentation induced by TBM with GFEM
}

\author{
XY Xu, XH Tang and QS Liu \\ School of Civil Engineering, Wuhan University, \\ Wuhan, China \\ xuxiaoyu0818@whu.edu.cn
}

\begin{abstract}
Theory about the interaction of TBM disc cutters and rock mass is critical for the design of the TBM machine. The numerical model of the interaction between cutters and rock, has important theoretical and practical meaning for developing a complete forecasting model of TBM performance. In this paper, one TBM disc cutter model is established based on finite element meshes. Then a model of full-face TBM cutterhead with several discs is presented for analyzing the strain distribution from start to rock failure. Meanwhile a Generalized Finite Element method (GFEM) simulation of a single crack propagation is shown in this paper. This numerical model simulates crack propagation under symmetrical loading and unsymmetrical load, respectively. The propagation path resulted in numerical simulation accords well to the laboratory tests.
\end{abstract}

Keywords-TBM; disc cutter; rock breaking; GFEM

\section{INTRODUCTION}

With the construction of expressway network and railway network, tunnel engineering has significant development in recent years. Tunnel Boring Machine (TBM) could be applied to almost all the rock conditions. With the advantages of TBM, such as efficiency, good tunnel molding, good performance of anti-disturbance and safety, this machine is widely used in underground engineering, especially tunnels with high water pressure and confining pressure. The interaction theory of TBM disc cutters and rock mass is critical for the design and usage of the TBM machine for underground engineering.

The interaction theory is not only the fundamental for rock breaking mechanism, but also the basis for the prediction of tunneling parameters when TBM excavating, which has important theoretical and practical meaning for developing a complete forecasting model of TBM performance[1]. Numerical method proposes effective ways for TBM rock breaking simulation.

Discrete element method (DEM) is widely used for rock fragmentation study. Su et al. used particle flow code (PFC) to study the influences of the angle and width of cutter rings on the cutter's fragmentation ability [3]. Finite Element Method (FEM) has some defects in simulating discontinuity. However, methods of the modified continue mechanics theories are able to simulate crack propagation without remeshing, including Generalized Finite Element Method (GFEM) and Extended Finite Element Method (XFEM)

Nowadays, the mechanism of interaction between cutters and rock is not completely clear. Additionally, the studies of

\author{
G Singh \\ Department of Mechanical Engineering, Campus, \\ BITS Pilani - KK Birla Goa, \\ Goa, India \\ gauravs@goa.bits-pilani.ac.in
}

rock breaking by full-face TBM cutterhead are still at starting stage. Moreover, there is a little work on the shape of crack under asymmetric loading.

In this paper, a single cutter disc model is established for analyzing rock breaking process. Meanwhile the full-face cutterhead model is proposed and the breaking process with multiple cutter discs is simulated. The distribution of stress is discussed. Rock fragmentation process induced by a single indenter, with symmetric and asymmetric loading. The simulated results accords well to the laboratory tests.

\section{DynAmiC AnAlysis of A Single Disc CUTter}

\section{A. Numerical simulation model}

Since the late 1970s, V-shaped cutter rings have been widely used for high cutting efficiency and long-term durability. We employed V-shaped disc cutter of $432 \mathrm{~mm}$ (17in.) in diameter, $80 \mathrm{~mm}$ in thickness and $121^{\circ}$ of the edge of angle(Fig.1).

The disc cutter is modeled as rigid body in this paper. The disc cutter model moves in horizontal direction ( $x$-direction) for linear cutting. At the same time, the cutter is fixed in the vertical direction to maintain a given depth, and the cutter rotates at a constant angular velocity of $2 \mathrm{~m} / \mathrm{s}$.

The granite rock is modeled as a rectangular parallelepiped, $1200 \mathrm{~mm} \times 1000 \mathrm{~mm} \times 600 \mathrm{~mm}$, using cubic elements. The input parameters for the rocks modeled in this section is determined based on the measured rock properties and is summarized in Table I. Meshes and boundary condition employed in the numerical model are shown in Fig.2.

There are two step for simulating procedure. The first step focuses on the rock-disc interaction when the cutter digs down.

TABLE I. MECHANICAL PROPERTIES OF THE GRANITE ROCK

\begin{tabular}{|l|l|}
\hline \multicolumn{1}{|c|}{ Item } & \multicolumn{1}{c|}{ Value } \\
\hline Density $\left(\mathrm{kg} / \mathrm{m}^{3}\right)$ & 2500 \\
\hline Young's modulus, $E(\mathrm{GPa})$ & 27.6 \\
\hline Uniaxial compressive strength $(\mathrm{MPa})$ & 150 \\
\hline Uniaxial tension strength $(\mathrm{MPa})$ & 4.6 \\
\hline Internal friction angle $\left(^{\circ}\right)$ & 53 \\
\hline Poison's ratio, $v$ & 0.3 \\
\hline Dilatancy angle $\left(^{\circ}\right)$ & 10 \\
\hline
\end{tabular}


The total time in this step is $5 \mathrm{~s}$. The second step focuses on understanding the $3 \mathrm{D}$ rock fragmentation process, and on reproducing the formation of groove. This step takes 10 seconds at all.

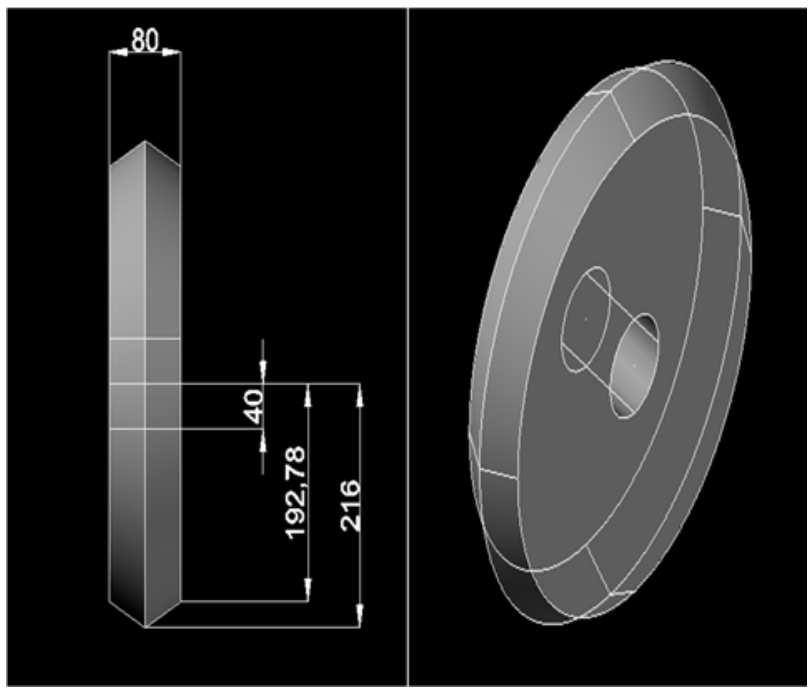

Fig.1V-shaped disc cutter: (a) Front view and dimensions (b) Three-dimension draft

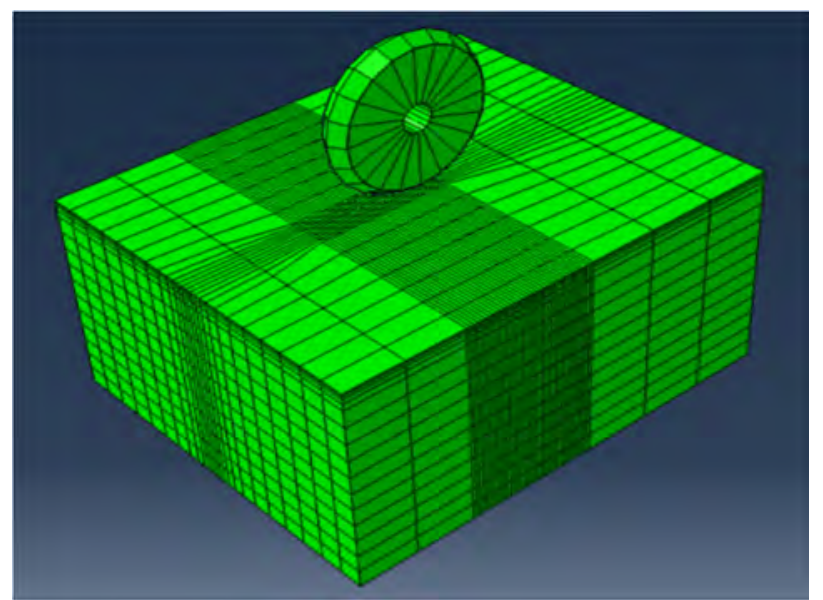

Fig.2 Mesh and boundary condition

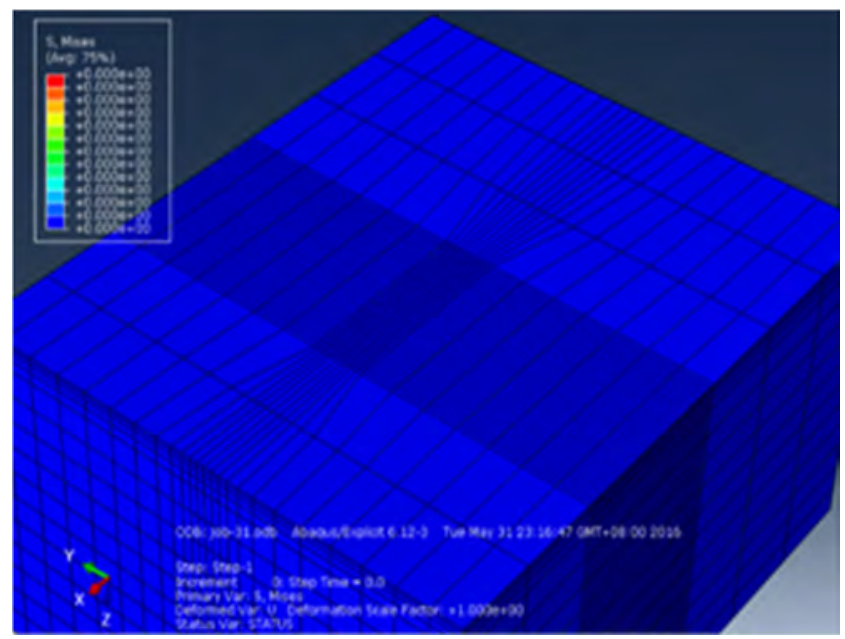

Fig.3 (a) Initial step, $\mathrm{t}=0$

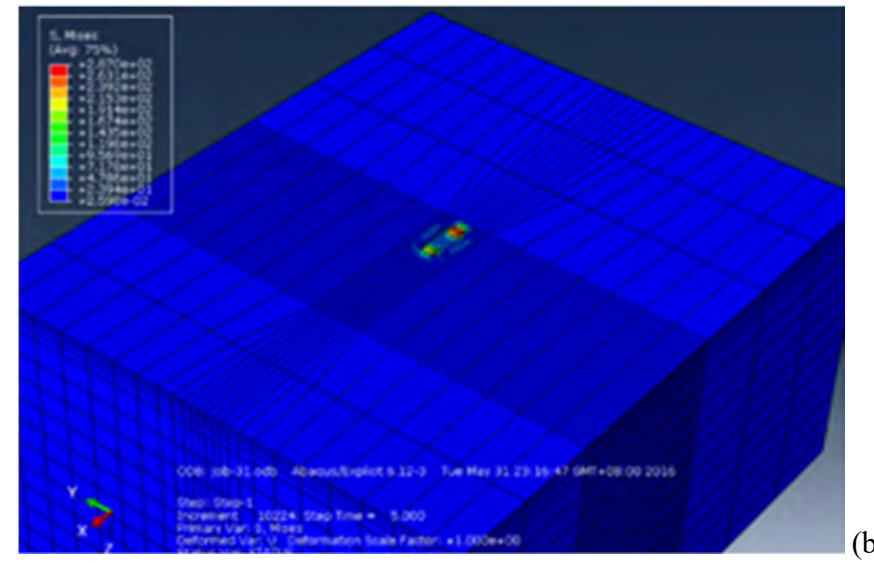

Fig.3 (b) Step 1, $\mathrm{t}=5 \mathrm{~s}$

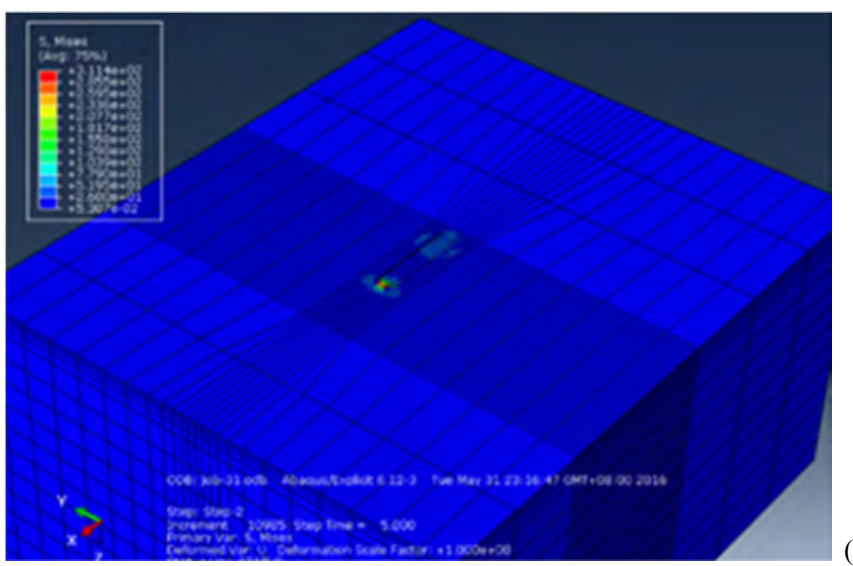

(c)

Fig.3(c) Step 2, $\mathrm{t}=10 \mathrm{~s}$

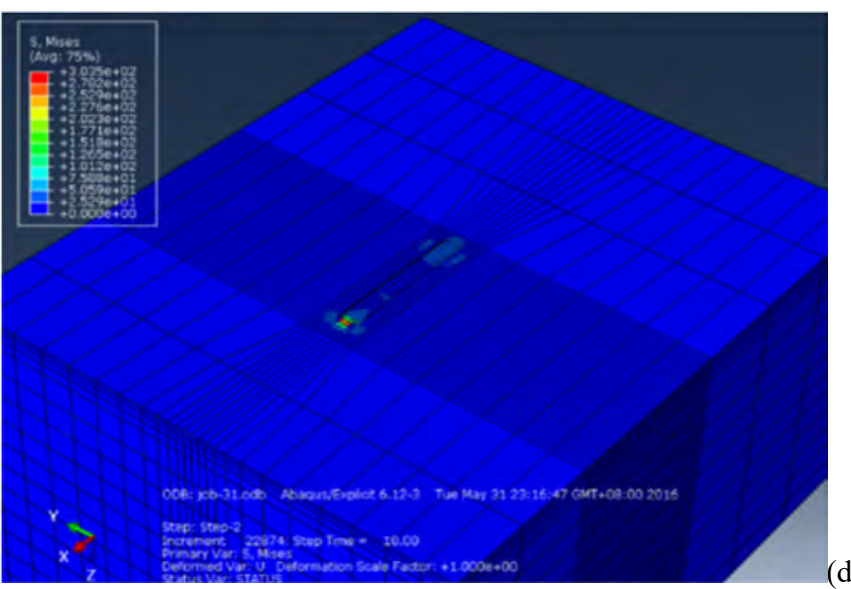

Fig.3 (d) Step 3, t=15s

Fig.3 Rock stress analysis when fragmenting with single TBM disc

\section{B. Dynamic results analyzing}

1) Entire Proceeding analyses: Since the stress distribution only exists in a small part of the rock, it will be clearer to observe the variation of stress when hiding the TBM cutter disc. The rock fragmentation process is captured in Fig.3. In the first step, the disc digs down with velocity of $0.001 \mathrm{~m} / \mathrm{s}$ and rotates with angular velocity of $6.28 \mathrm{rad} / \mathrm{s}$. As shown in Fig.3a, the disc do not connect with rock, thus Mises stress is 0 . 


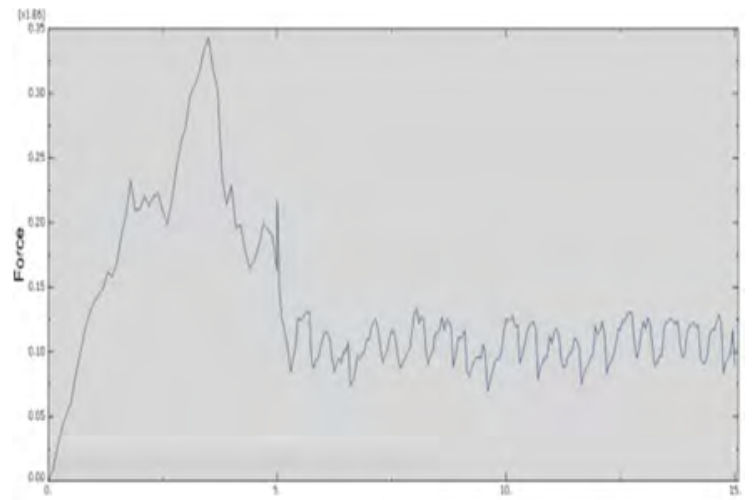

Fig.4 The normal counterforce of disc reference point

With the downward of disc, a fan-shaped stress zone appears and radiates. The maximum stress is at the touch point of disc cutter. The longer distance to touch point is, the small stress shows. The Mises stress presents an approximate axial symmetric distribution, and with the penetration of disc, the value of maximum stress increases as well.

Step 2 starts when Step 1 ends (Fig. 3b), and finishes at Fig. $3 \mathrm{~d}$. In this step, the disc keeps $5 \mathrm{~mm}$ in penetration and $6.28 \mathrm{rad} / \mathrm{s}$ in rotational velocity. The rock is cut along the trace of disc with the speed of $0.04 \mathrm{~m} / \mathrm{s}$. This step reproduces the dynamic process of rock breakage and groove formation. Pressure Analyses in Step 1: Different penetrations can be achieved by controlling the advancing rate and the rotational speed of the propel cylinders and the driving motors, respectively.

As shown in Fig.4, the plane of $y-z$ is used for analyzing pressure. When the normal force of cutter acts on rock, firstly it presents the linear elastic stage (in Fig. 4a-4d). As with the more penetration, it shows a highly stressed zone comes into being immediately beneath the cutter. Fig 4e shows where rock stress reaches the critical stress, rock experiences plastic deformation and then gets failure. At the crush stage (Fig. 4f), the contact stress at the stress zone decreases.

The normal counterforce curve and the tangential counterforce curve at the disc reference point are presented in Fig. 4 and Fig. 5, respectively. In these two pictures, it is found that when time is 3.5 seconds, the maximized counterforce value is reached. It should be noted that the failure of rock occurs when the counterforce starts to decrease. Thus, the best penetration of cutter could be $4 \mathrm{~mm}$ in this condition. In the penetration process, the maximum normal and tangential counterforce is $350 \mathrm{KN}$ and $120 \mathrm{KN}$, respectively. In the rolling process, the average normal counterforce is $100 \mathrm{KN}$, and the average tangential counterforce is $20 \mathrm{KN}$, respectively.

\section{DYNAMIC ANALYSIS OF A FULL-FACE TBM CUTTERHEAD}

In order to study cutterhead mechanical performance in a certain condition, a FEM model is generated, as shown in Fig. 7. The crucial issue of the model is to understand the rock behaviors under each individual cutter during the boring process. The cutterhead, with diameter $8030 \mathrm{~mm}$, is mounted with 23 normal disc cutters (cutter diameter 17 in./432 mm). The disc cutters, the bearings and protective boxes are printed in CATIAv6.

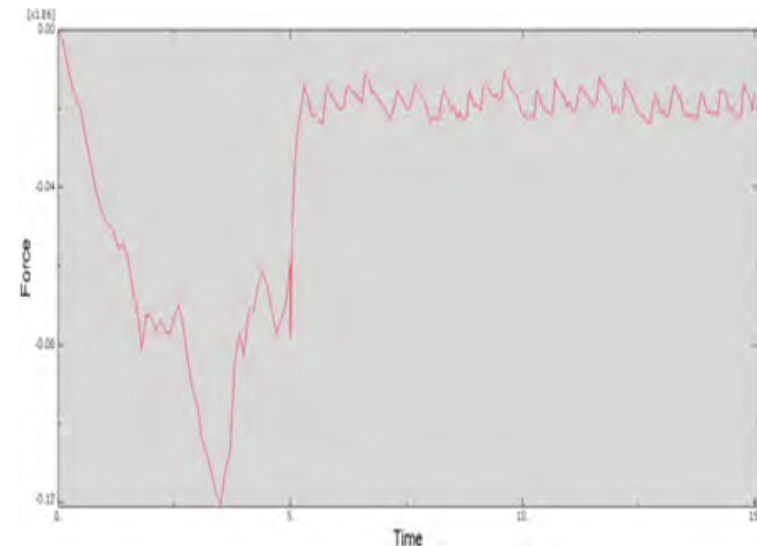

Fig.5 The tangential counterforce of disc reference point

The granite rock is modeled as a rectangular parallelepiped, $1200 \mathrm{~mm} \times 1000 \mathrm{~mm} \times 600 \mathrm{~mm}$, using cubic elements. The input parameters for the rocks modeled in this section is the same with rocks in chapter two, as seen in Table I.

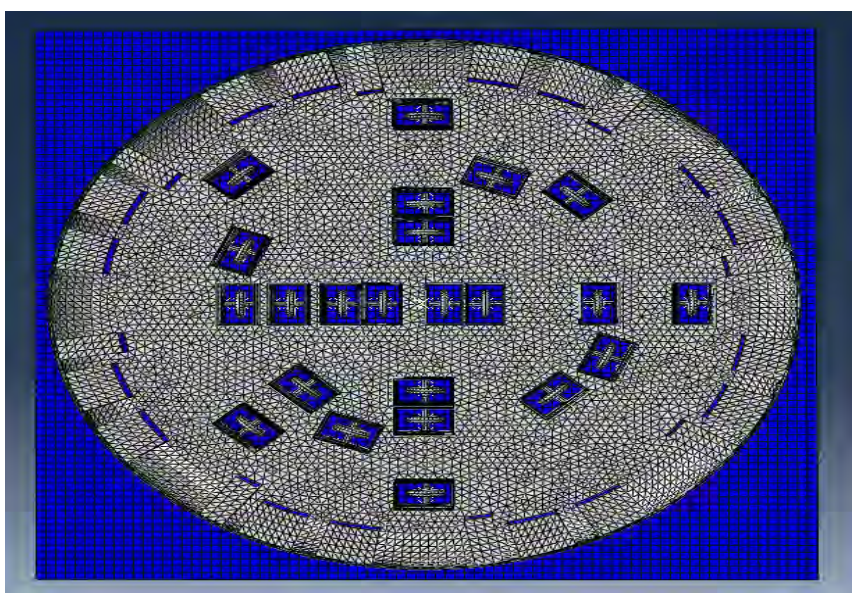

Fig.6 The full-face TBM cutterhead analyzing model.

The whole simulation could be divided into three steps. The interactions are debugged in Step 1. Step $2(\mathrm{t}=20 \mathrm{~s})$. As shown in Fig.8, at Step $3(\mathrm{t}=60 \mathrm{~s})$ of rock breaking process, multiple cutters cut rock simultaneously when cutterhead rotates, is analyzed. Here, cutterhead is hidden for a better presentation. The stress analysis (Step3) of full-face TBM cutter-head is presented in Fig.7.

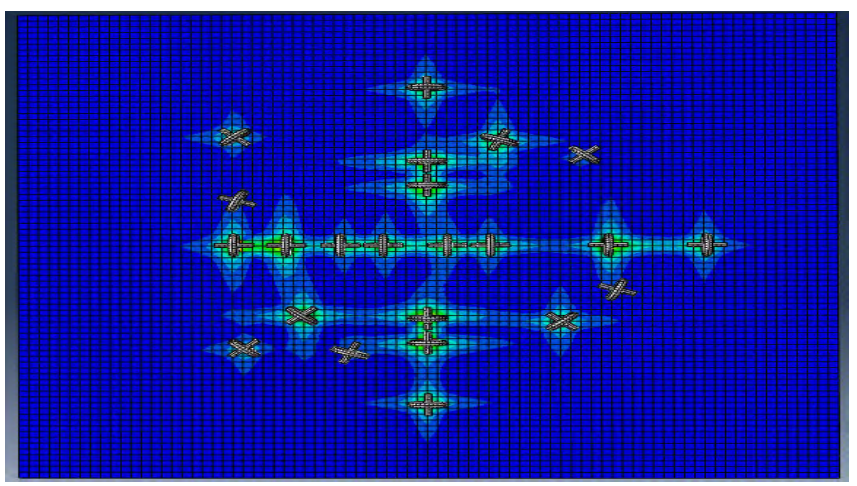

Fig.7 (a) Step3, t=20s 


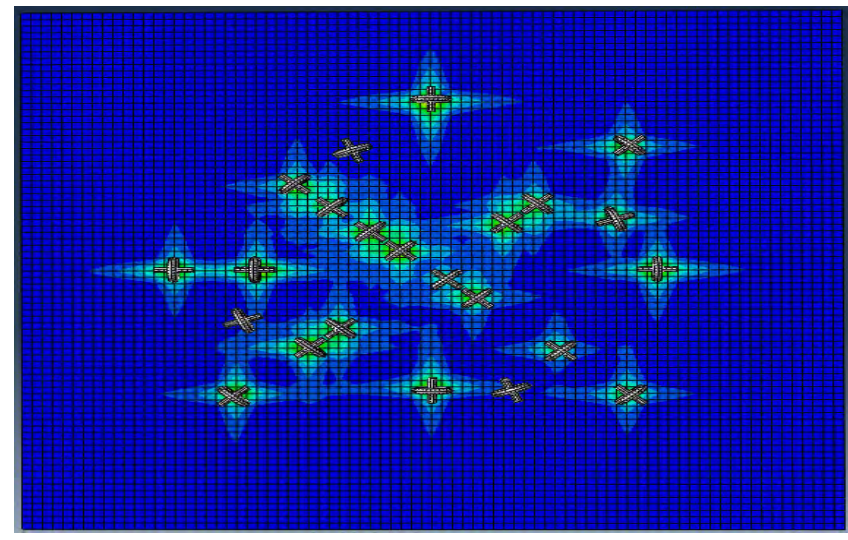

Fig.7 (b) Step 3, $\mathrm{t}=25 \mathrm{~s}$

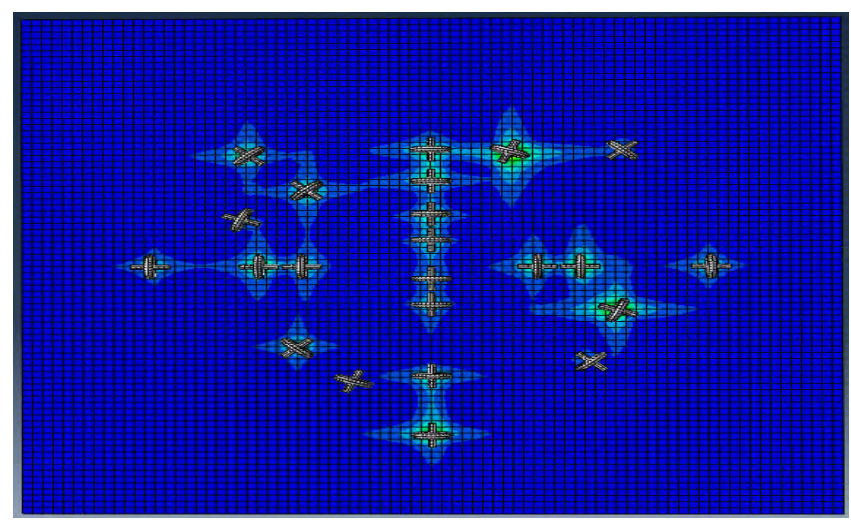

Fig.7 (c) Step 3, t=30s

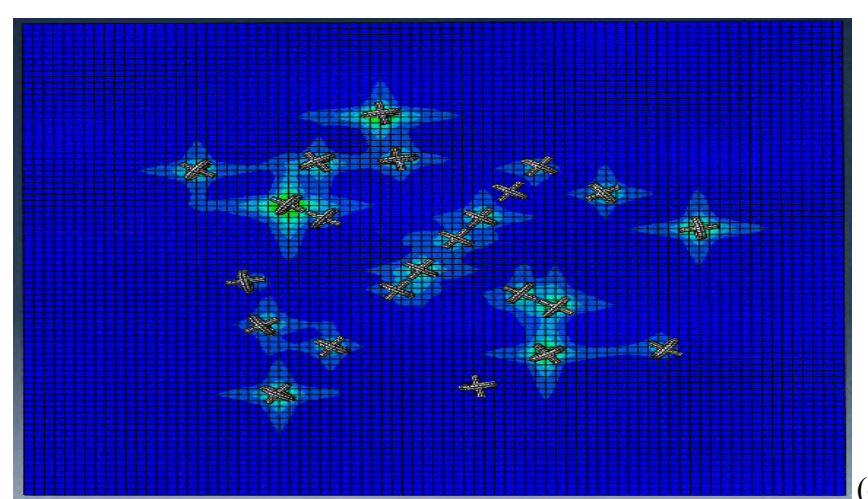

Fig.7 (d) Step 3, t=35s

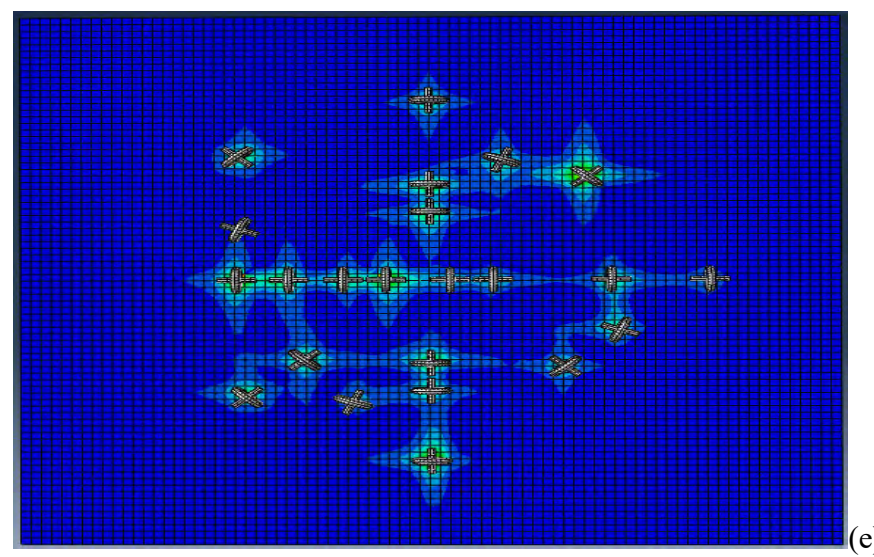

Fig.7 (d) Step 3, t=40s

Fig.7 rock stress analysis when fragmenting with multiple TBM cutters

\section{3D Rock Fragmentation With A SingLe CUTTER}

\section{A. Introduction of high-order GFEM}

GFEM is an effective method for crack propagation. The dimension of global stiffness matrix increases during crack propagation simulation in the traditional FE-Shepard GFEM. This high-order GFEM is a development of hybrid 'FE-Meshfree' method, which keeps the computational accuracy and stability during the simulation of crack propagation.

In this paper, this high-order GFEM is used to simulate crack propagation. Additionally, Rankine Criterion is used for determing the fracture initiation and propagation. When the maximum stress of brittle rock reaches the tension strength, macrocrack shows up and rock fails. Rankine Criterion is written as:

$$
\sigma_{1}{ }^{\text {front }}=T_{0}
$$

where $T_{0}$ is the tension strength, $\sigma_{1}{ }^{\text {front }}$ is the maximum tension stress in crack tip.

\section{B. Simulation of indentation experiments}

A series of the indentation experiments were conducted on marbles with varying relative confinement and wedge angles by Chen [8].

TABLE II. MECHANICAL PROPERTIES OF THE MARBLE

\begin{tabular}{|l|l|}
\hline \multicolumn{1}{|c|}{ Item } & \multicolumn{1}{c|}{ Value } \\
\hline Density $\left(\mathrm{kg} / \mathrm{m}^{3}\right)$ & 2500 \\
\hline Young's modulus, $E(\mathrm{GPa})$ & 68 \\
\hline Uniaxial compressive strength $(\mathrm{MPa})$ & 210 \\
\hline Uniaxial tension strength $(\mathrm{MPa})$ & 13 \\
\hline Poison's ratio, $v$ & 0.22 \\
\hline
\end{tabular}

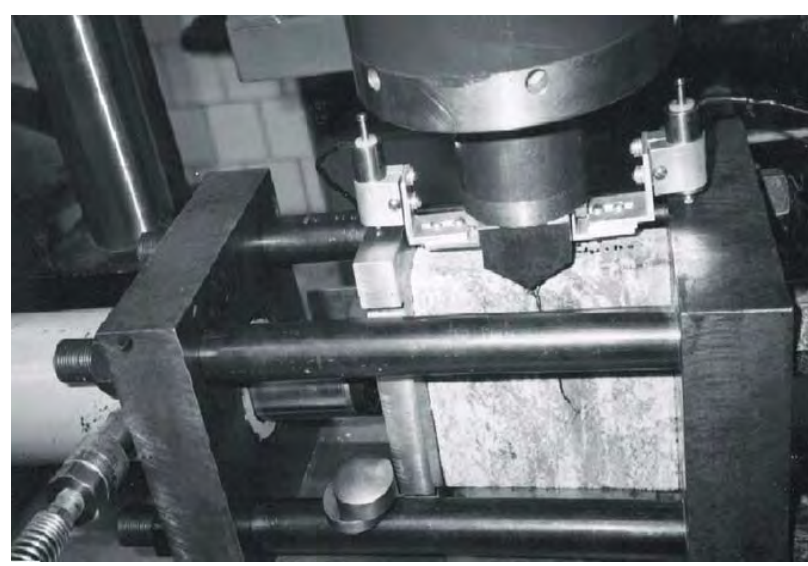

Fig. 8 Indentation apparatus by [8]

A two-dimensional indentation apparatus was designed (Fig. 8), with a closed-loop, servo-hydraulic loading system to generate the indentation force and a horizontal reaction. The material properties are indicated in Table II.

The rock model is fabricated with wedge-shaped groove and preset crack. The dimensions of rock are $120 \mathrm{~mm}$ in width, 
$5 \mathrm{~mm}$ in thickness and $60 \mathrm{~mm}$ in height (shown in Fig.9). The model is imported into the high-order GFEM simulator. Fig 10 and Fig 11 are the mesh and initial crack, respectively.

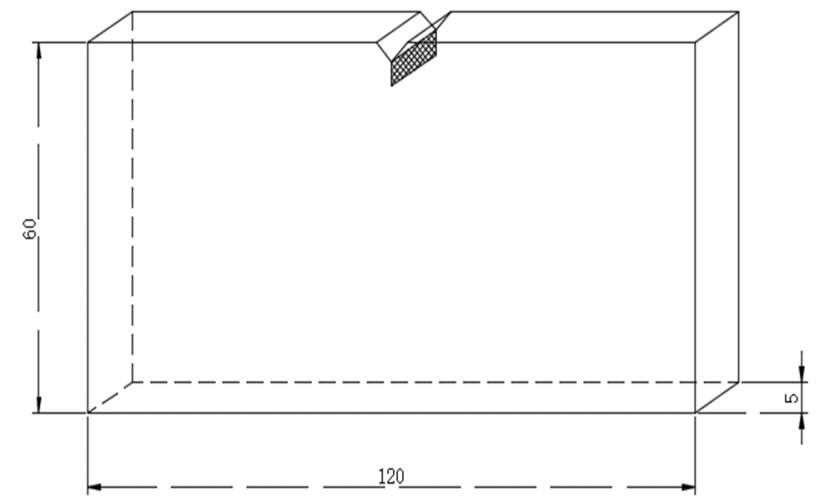

Fig.9 dimensions, wedge-shaped groove and preset crack

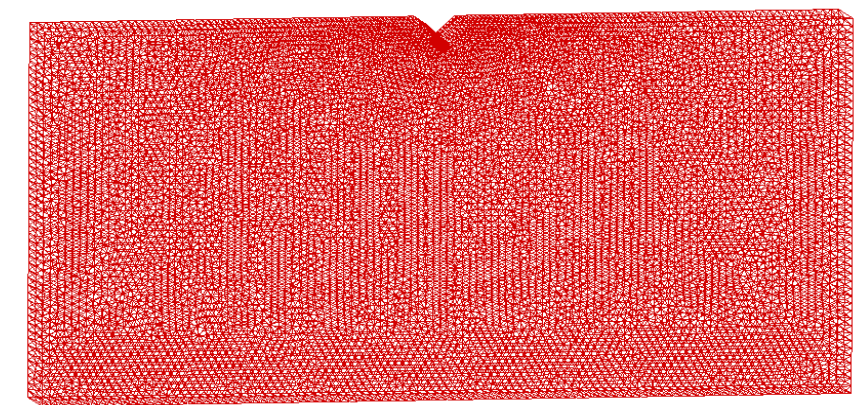

Fig.10 Mesh for high-order GFEM simulation

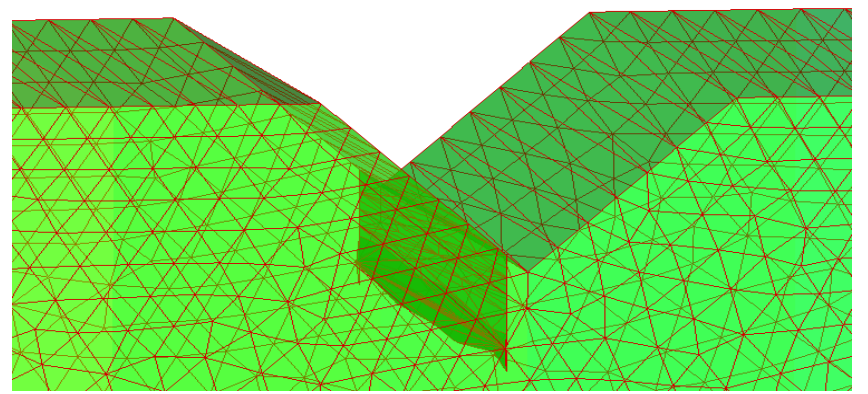

Fig.11 Initial crack

\section{Numerical results under different loadings}

1) Symmetrical loading results: Fig. 12 shows $\mathrm{AE}$ locations for an unconfined case using penetration as the feedback signal by Chen [8]. The corresponding AE locations (Fig. 12) defines the AE cluster located at a certain depth below the indenter. And the fracture propagates from upper to lower. Fig. 13 presents the results from GFEM, which corresponds to the laboratory test.

2) Asymmetrical loading results: The AE locations in Fig.16 is the results of asymmetric loading by Chen. The fracture propagates from upper to lower and deviate the central axis. In Fig.14, the propagation path is also similar to the path by Chen and Fig. 15 represents sub vertical crack propagation path by high-order GFEM.

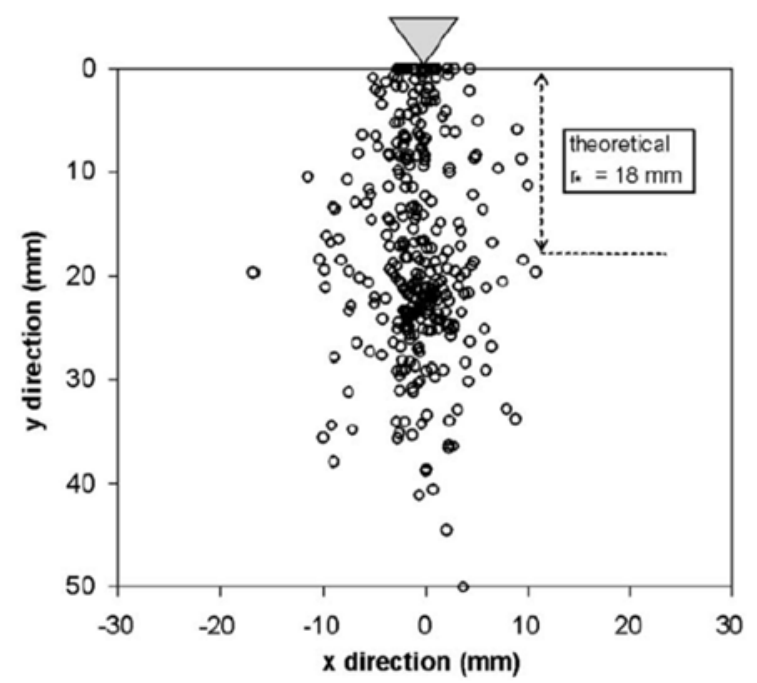

Fig.12 AE locations under symmetric loading for marble

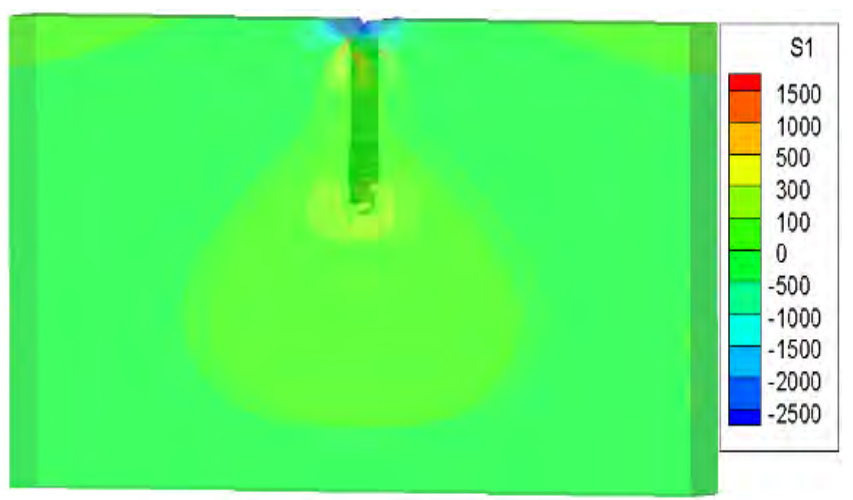

Fig. 13 Vertical crack propagation path by high-order GFEM

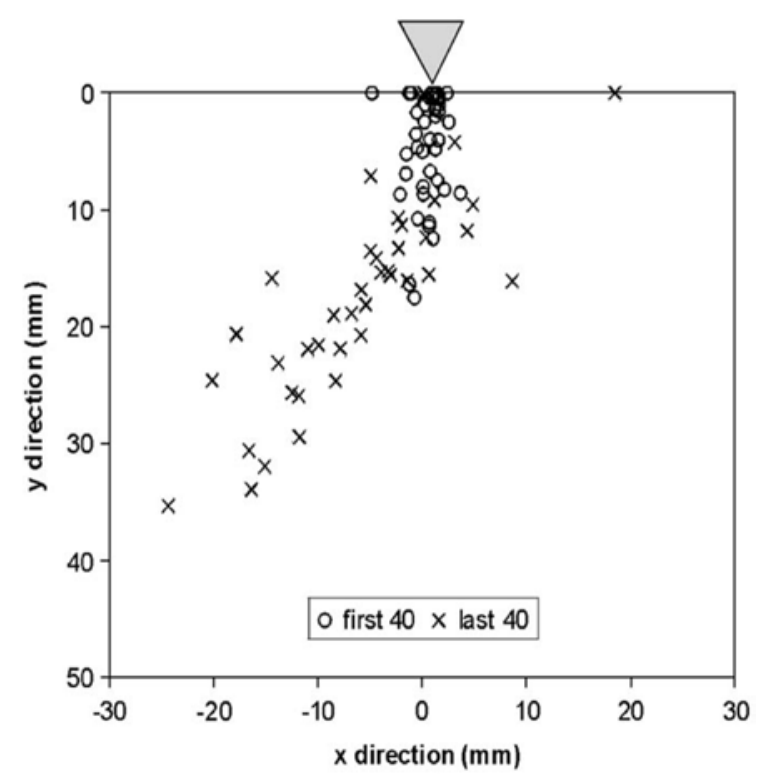

Fig. 14 AE locations under asymmetric loading for marble 


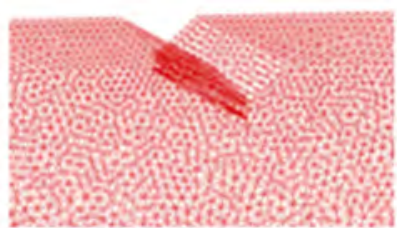

(a) Step 1

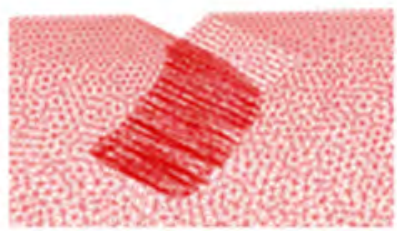

(c) Step 3

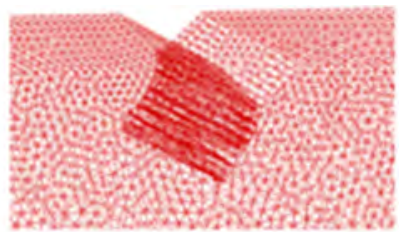

(b) Step 2

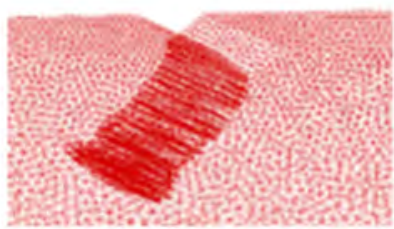

(d) Step 4
Fig.15 Sub vertical crack propagation path by high-order GFEM

\section{CONCLUSIONS}

- FEM is used to simulate a single disc cutter breaking granite rock. The pressure in the penetration stage is analyzed, as well as the counterforce. Thus, a better penetration depth is optimized, which has significant meaning in TBM cutters' design.

- The full-face TBM cutterhead model is also established using FE meshes. This model is simulated for analyzing the influences on rock breaking by multiple cutters.

- The propagation of a single crack is simulated using high-order GFEM. Symmetric loading and Asymmetric loading are applied to the rock with wedge-shaped groove. The numerical results agree well with the laboratory results.

\section{ACKNOWLEDGEMENT}

Financial support from the Ministry of Mines (Government of India), through project No. 14/22/2015-Met IV (2016-2019); the National Basic Research Program of China (973 Program), under the Grant No. 2014CB046900.

\section{REFERENCES}

[1] LIANG Zhengzhao, WANG Yan, LIAO Zhiyi, YANG Yuefeng "Current situation and developing trends of research on rock-breaking by cutters", Advances in Science and Technology of Water Resources, vol. 34, no. 2, pp 85-94, 2014

[2] A. Paluszny, X.H. Tang, and R.W. Zimmerman, " A fracture- and impulse-based FDEM approach for fragmentation". Computational Mechanics, vol. 52, no. 5, pp 1071-1084, 2013

[3] SU Li-jun, SUN Jin-shan, LU Wen-bo. "Research on numerical simulation of rock fragmentation by TBM cutters using particle flow method", Rock and Soil Mechanics, vol. 30, no.9, pp 2826-2829, 2009.

[4] X.H. Tang, X.Y. Xu, Q.S. Liu. "Modeling nonplanar propagation of 3D hydraulic fractures using high-order GFEM". ARMA 2016, 26-29 June, Houston, USA

[5] C.A. Duarte, I. Babuka, and J.T. Oden. " Generalized finite element methods for threedimensional structural mechanics problems", Computer \& structure, vol. 77, no. 2, pp 215-232, 2000.

[6] T. Belytschko, T. Black, "Elastic crack growth in finite elements with minimal remeshing". International Journal for Numerical Methods in Engineering, vol. 45, pp 601-620, 1999

[7] Y.T. Yang, X.H. Tang, H. Zheng, Q.S. Liu, L. He, "Three-dimensional fracture propagation with numerical manifold method", Engineering Analysis with Boundary Elements, in press.
[8] L.H. Chen, J.F. Labuz. "Indentation of rock by wedge-shaped tools". International Journal of Rock Mechanics and Mining Science, vol. 43, pp 1023-1033, 2006 